\title{
Greek Consumers' Behaviour Towards Fast-Food Consumption
}

\author{
Aldrina Jashari ${ }^{1} \&$ Panagiotis Kotsios ${ }^{1}$ \\ ${ }^{1}$ Business Department, Perrotis College, Thessaloniki, Greece \\ Correspondence: Panagiotis Kotsios, Business Department, Perrotis College, Thessaloniki, Greece. E-mail: \\ panagiotiskotsios@gmail.com
}

Received: May 20, 2019 Accepted: July 25, 2019 Online Published: August 19, 2019

doi:10.5539/ijms.v11n3p73 URL: https://doi.org/10.5539/ijms.v11n3p73

\begin{abstract}
Fast food has become a very popular nutritional habit for consumers and a billion dollars market for businesses across the world. As in most countries, in Greece there are thousands of fast food businesses that aim at satisfying the growing demand for fast food. However, there is lack of research about the behaviour of Greek consumers regarding fast food consumption. On this context, the goal of this research was to investigatethe frequency of consumption in Greece, the most popular types of fast food, the criteria with which consumers make consumption decisions and the environmental, economical, ethical, cultural and psychological factors that influence their buying behaviours. The results of the research show wide popularity of fast food consumption among Greek consumers and a clear trend towards healthy, tasty, easily accessible and not necessarily low-cost fast food.
\end{abstract}

Keywords: fast food, Greece, consumer behaviour, questionnaire

\section{Introduction}

Fast food has become a very popular nutritional habit and a huge market across the world. As in most countries, in Greece there are thousands of fast food businesses that aim at satisfying the growing demand for fast food. However, there is lack of researches about the behaviour of Greek consumers regarding fast food consumption. On this context, the goal of this research was to investigate the frequency of consumption in Greece, the most popular types of fast food, the criteria with which consumers make consumption decisions and the environmental, economical, ethical, cultural and psychological factors that influence their buying behaviour. To answer these questions, this research used a questionnaire approach on a sample of Greek consumers and the replies that were received were analysed in order to draw conclusions and identify market trends.

\section{Literature Review}

\subsection{Consumer Behaviour}

The discipline of Consumer Behaviour was developed from the early theories about Motivational Research. Motivation Research "represents the introduction into consumer or market research of new concepts drawn from the whole range of the social sciences, especially clinical psychology, sociology, and anthropology" (Gardner, 1959, p. 36). According to Martineau (1957) human behaviours are shaped both genetically and environmentally, meaning that humans' personality as well as their buying behaviour are affected through environmental interactions. With the goal to record and analyse these interactions, Motivation Research developed over the years in the marketing section; whereas in its improvement has added numerous of behavioral sciences such as clinical psychology, sociology, anthropology, and an assortment of areas of economics (Fullerton, 2011). The more descriptive field of Motivation Research became known as Consumer Behavior.

Solomon, Bennett and Previte (2013) defined the field of consumer behaviour as: "the study of the processes involved when individuals or group select, purchase, use or dispose of products, services, ideas or experiences to satisfy needs and desires" (p. 3). Furthermore, Schiffman et al. (2014) claimed that consumer behaviour is the consumers' actions undertaken while searching for the purchase, use and estimation of a product/service that might possibly fulfil their necessities and desires. Another definition proposed by Khan (2008), is that consumer behaviour is the decision-making process and physical activity involved in acquiring, evaluating, using and disposing of goods and services.

According to Noel (2009), consumers' final purchasing decision is a result of a deliberation of internal and 
external factors on products' features and the utility that they may receive from its purchase. The factors influencing purchasing decisions can be divided into three categories: a) External Factors; b) Internal Factors; and c) Post-decision processes. The external factors identify demographic parameters such as gender, family status, job, income, cultural variables, ethnicity, religion, geographic differences etc. Different cultures, religions, individualistic ethics/morals and values refer to different norms, rituals and habits that essentially affect one's final purchasing decisions (Egan, 2007). On the other hand, there are internal processes as psychographic factors including: buyer's personality, thought processes, mood, knowledge, perception, brand commitment and so forth. Additionally, brand awareness is a factor that influences costumers' buying decisions; a fact that justifies marketeers' emphasis in advertising and promoting (Noel, 2009). Moreover, the post-decision process is another indicator of the overall purchase/consumption/usage satisfaction of a particular product/service. Consumer's post-purchase satisfaction will determinate if the buyer will continue to buy a product, and if they transmit positive messages to other consumers. This particular research's focus is on consumer behaviour in relation to fast food.

\subsection{Fast Food Consumption}

Fast Foods are defined as: "inexpensive foods served in restaurant chains, where orders are served promptly at a counter" (Smith, 2012, p. 316). They are cheap alternatives to home-cooked meals, quick and easily to access. However, this category of foods is known for a low nutritional value, rich in sugar, salt, saturated fats, sodium and fatty calories, even though some healthier alternatives are being added into food chains' menus (Smith, 2012). Common types of fast foods include burgers, pizza, sandwiches, hot-dogs, cold sandwiches, tacos, nachos, modified vegetarian and non-vegetarian wraps etc. There is no doubt that this industry has significantly changed the way people eat and their overall life style. Factors that influence fast food consumption include gender, age, academic background, income and mood, while the purchasing decision is based in product characteristics such as quality, taste, price, preparing time, convenience, availability etc (Wansink, 2004). Jekanwoski, Binkley and Eales (2001) claimed that fast food consumption growth has been affected fundamentally by its price \& accessibility.

According to many studies that explored the growth demand in fast food consumption (e.g., Byrne et al., 1996; Sexauer, 1979; Kinsey, 1983), convenience has been pointed out as one of the most important factors influencing fast food consumption. This food category fits best nowadays people's busy lifestyles, since time limitation is high and many people don't want to spend a lot of time in the process of preparing a meal or accessing one. Moreover, fast food outlets complete the nutritional needs of this over-scheduled society by being tasty, convenient, highly accessible, inexpensive and fast (Jekanowski, Binkley, \& Eales, 2001). Grunert (2005) in his research concluded that food quality and safety are also central issues in today's food economics. Moss (2013) in his book examined processed food and its addictive implications, and claimed that the industry's food scientists have discovered the 'holy trinity': the precisely engineered combination of salt, sugar and fat, calculatingly designed to be irresistible and addictive, assuring a never-ending demand for these products. In addition, fast food ads and commercials are very appealing and desirable using various physiological techniques and eye-catchy colors in order to stimulate the desire for consumption.

By the time this food category gained popularity and loyal customers attributable to its advantages, its disadvantages started to be known as well. Fast food consumption started to be alarming due to the rise of health problems among consumers (Allahar, 2015). Fast food consumption has been linked with obesity (Davis \& Carpenter, 2009; Marlow \& Shiers, 2012), and obesity is linked to several diseases such as diabetes, hypertension, heart disorders, strokes, cancers etc. These facts have created a big discussion about the health implications of fast food on humans, especially in the young ages (Poti, Duffey, \& Popkin, 2014). Individuals might be personally guilty for their eating habits and choices, but also, aggressive promotions and advertising have a significant influence on un-healthy food consumption in daily bases, especially to the young generation (Buttriss, Deakin, \& Smith, 2003). Another issue that was raised in relation to the fast food industry was related with animal mistreating through intensive farming (Dentoni et al., 2011). In order to ease consumer concerns, nowadays many fast food chains provide consumers with nutritional information about their menu, are trying to be more conscious about products' nutritional values and provide healthier alternatives (Gregory, McTyre, \& DiPietro, 2006).

\subsection{Fast Food Consumption in Greece}

Greece is a Mediterranean country with a population of 10,816,286 habitants, out of which $51 \%$ are female and $49 \%$ male. The distribution of the population in age groups is 0-19:19\%, 20-39: $28.7 \%, 40-59: 27.4 \%$ and the rest $24.9 \%$ is over 60 (Hellenic Statistical Authority, 2018). The Greek traditional diet is regarded as an 
important variant of the Mediterranean diet, which is considered as very healthy and protective against disease - especially heart disease and cancer (Keys \& Keys, 1975; Vernele et al., 2010; Lacirignola \& Capone, 2015). Traditionally, due to their dietary and lifestyle practices, the Greeks have a very good health and life expectancy record. The habitants of the island of Crete have a life expectancy of 82 years and perhaps not surprisingly, the highest consumption of olive oil (25 litres per capita) in the world (Kromhout, Menotti, \& Blackburn, 1994). The Greek traditional diet is based largely on fresh, unprocessed seasonal product. It is low in saturated fat and high in dietary fibre, starch, antioxidant vitamins (from cereals, fruit and vegetables) and polyphenols (from wine and olive oil) (Trichopoulou et al., 2014).

Despite all the advantages of the authentic Greek diet; Greeks' eating habits have started to transform from the patterns of a plant-based diet low in saturated fats into a more 'Westernised' food consumption behaviour, mainly based in meat (Hu, 2003). The most popular street-fast foods found nowadays in Greece are 'gyros' and 'souvlaki', burgers, pizzas, crepes and sandwiches. Fast foods are popular especially among youngsters and people that are away from home for many hours per day. According to Giannatou (2013), Greeks prefer traditional snacks like souvlaki and pies instead of fast food from large multinational fast food chains. A recent study by Euromonitor (2018) also claims that independent fast food businesses outperform chained fast foods. However, the actual eating habits and preferences of Greeks in regard to fast food consumption remain unexplored, as there is a lack of research on this specific topic. In this context, the current research tried to record and analyse Greeks' opinions about fast food and its consumption. Particularly, the research tried to investigate the following questions: a) If people in Greece consume fast food and how frequently, b) the types of fast food they prefer, c) which are the criteria for choosing fast food and d) the factors that affect their consumption patterns.

\section{Methodology}

For the purpose of answering the above questions, the researchers chose to collect primary data through a survey on Greek consumers with the use of print and online anonymous questionnaires. The print questionnaire was handed out in the center of the city of Thessaloniki, the second largest city in Greece in population. The questionnaire consisted of three parts: the first part asked for demographic information such as age, gender, family status, educational level and income; The second part included close ended questions that had to do directly with fast food consumption frequency, preferences, intake habits and the factors that affect them, as well as four more general questions; and the third section consisted of one open-ended question relating to respondents' viewpoints about fast food and some free space for general comments.

The questionnaires were handed out in two different time periods (January 2016 and June 2017), for a period of 1 month (30 days) each time. Only Greeks and persons living permanently in Greece were allowed to complete the questionnaire (tourists were excluded), but there wasn't any other limitation regarding the characteristics of the sample population. Before completing the questionnaire, both in the online and hardcopy format, the participants were provided with a description of the research project and were given the contact details of the researchers. In total 200 questionnaires were gathered during the first period and 199 during the second. From the questionnaires 340 were completed electronically and 59 in paper. According to the Greek population of $10,816,286$, the size of the sample (399 respondents) gives a $4.91 \%$ margin of error with a $95 \%$ confidence level.

\section{Results}

The analysis of the results is presented in the sequence of the questionnaire: The 1st part presents demographic information about the respondents, the 2 nd part analyses their answers regarding fast food consumption and the 3rd part summarizes the answers of the open-end questions.

\subsection{Demographic Information}

The demographic information that was asked from the respondents was related with their age, gender, family status, educational level and income.

\subsubsection{Age}

Table 1 presents information about the age of the respondents. Age has been divided in 6 age groups: $<20$, 21-30, 31-40, 41-50, 51-60 and over 60 . Table 1 presents both the number of responses in each group and the percentages. 
Table1. Age of respondents

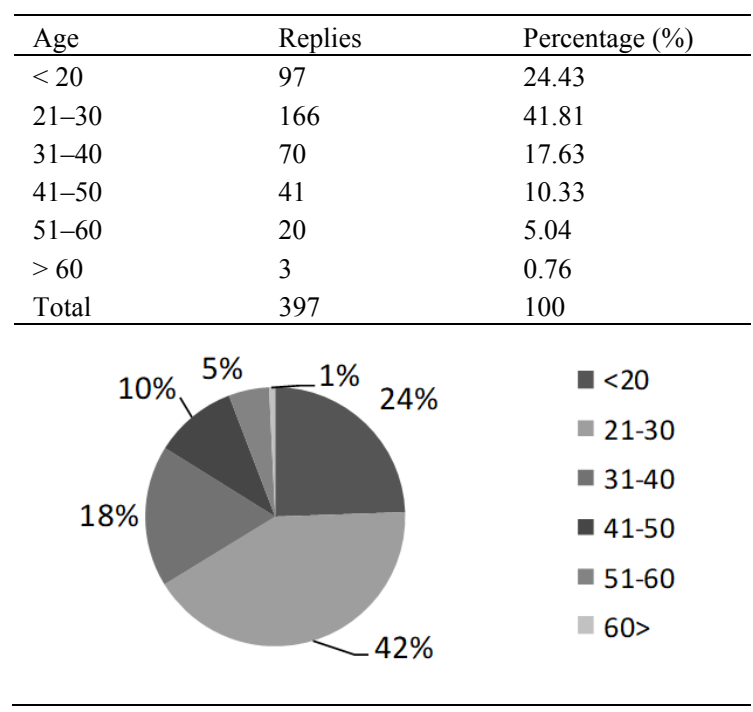

From the table it is noted that most of the respondents were between 21 to 30 years old $(41.81 \%)$. Second age group in frequency was that of under $20(24.43 \%)$, followed by the age group $41-50(17.63 \%)$. The percentage of respondents in the age groups 51-60 and over 60, are small and under the national average. This is mainly due to the fact that computer literacy in these ages in Greece is limited.

\subsubsection{Gender}

Table 2 presents information about the gender of the respondents. Apart from male and female the option Other was given in order to cover cases of people that didn't have a clear gender identity.

Table 2. Gender of respondents

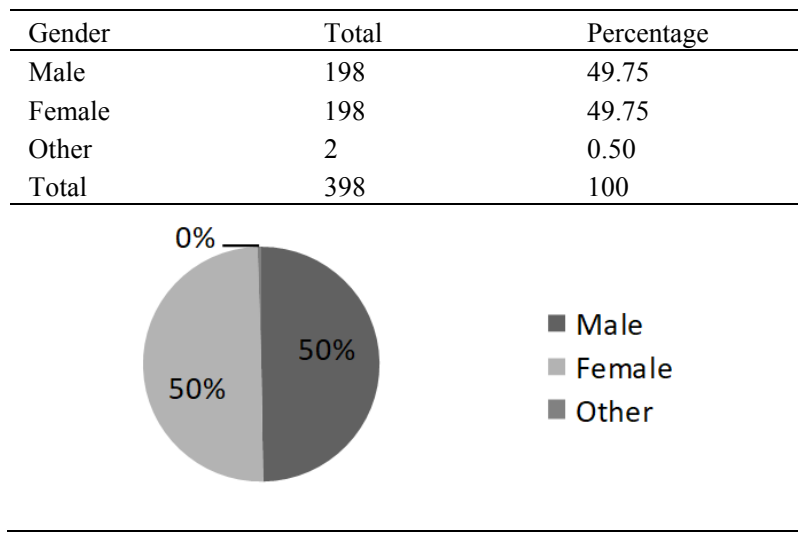

According to Table 2, half of the respondents were female and half male. Two of the respondents didn't define a gender. These statistics are in line with the national averages.

\subsubsection{Income}

Table 3 presents information about the yearly incomes of the respondents. Incomes are divided in 12 categories, starting from incomes below $10.000 €$ and ending to incomes over $90,000 €$. 
Table 3. Gender of respondents

\begin{tabular}{|c|c|c|}
\hline Income (Yearly) & Total & Percentage \\
\hline Up to $9,999 €$ & 191 & 48.60 \\
\hline $10,000 €-14,999 €$ & 89 & 22.65 \\
\hline $15,000 €-19,999 €$ & 40 & 10.18 \\
\hline $20,000 €-24,999 €$ & 23 & 5.85 \\
\hline $25,000 €-29,999 €$ & 10 & 2.54 \\
\hline $30,000 €-39,999 €$ & 12 & 3.05 \\
\hline $40,000 €-49,999 €$ & 5 & 1.27 \\
\hline $50,000 €-59,999 €$ & 2 & 0.51 \\
\hline $60,000 €-69,999 €$ & 6 & 1.53 \\
\hline $70,000 €-79,999 €$ & 0 & 0 \\
\hline $80,000 €-89,999 €$ & 6 & 1.53 \\
\hline More than $90,000 €$ & 9 & 2.29 \\
\hline Total & 393 & 100 \\
\hline $3 \%$ & $2 \%$ & $\begin{array}{l}\text { Under } 9.999 € \\
10,000 €-14,999 € \\
\square 15,000 €-19,999 € \\
\square 20,000 €-24,999 € \\
25,000 €-29,999 € \\
30,000 €-39,999 € \\
40,000 €-49,999 € \\
50,000 €-59,999 € \\
60,000 €-69,999 € \\
\square 0,000 €-89,999 € \\
\text { More than } 90.000 €\end{array}$ \\
\hline
\end{tabular}

This question was replied by $98.7 \%$ of the respondents. Most of them $(48,60 \%)$ stated that their income was up to $9,999 €$. Next in frequency was the income scale of $10,000-14,999 €$ with $22.65 \%$, followed by the income scale $15,000-19,999 €$ with $10.18 \%$. Only 9 of the respondents $(2.29 \%)$ had incomes over $90,000 €$. It is worth noting that according to published tax data from the Greek Ministry of Finance for the year 2017, $73 \%$ of Greek taxpayers had a yearly income below 15.000 euro.

\subsubsection{Family Status}

Table 4 presents information about the family status of the respondents. The options given were single, married, divorced and other (refering in cases of separated couples).

Table 4. Family status

\begin{tabular}{lll}
\hline Family status & Total & Percentage \\
\hline Single & 244 & 62.24 \\
Married & 99 & 25.26 \\
Divorced & 20 & 5.10 \\
Other & 29 & 7.40 \\
Total & 392 & 100 \\
\hline
\end{tabular}

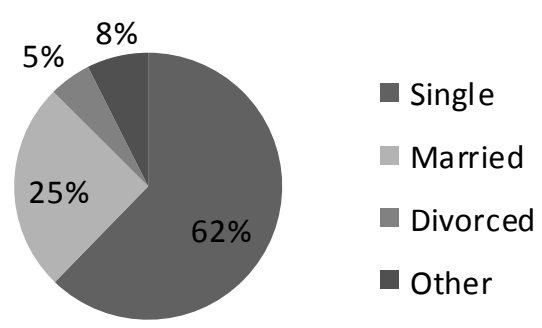


From the respondents $62 \%$ were single, $25 \%$ married, $5 \%$ divorced and $8 \%$ declared Other. The high percentage of single population in the sample can be explained by the fact that $24 \%$ of the sample population was $<20$ and $41 \%$ was between 21 and 30 years old. It is noted that the average marriage age in Greece is 31,5 years.

\subsubsection{Educational Level}

Table 5 presents information about the respondents' educational level. The options given included secondary and tertiary education, masters, doctorate and other (in order to cover only primary education cases). It is noted that finishing primary education in Greece is obligatory by law.

Table 5. Educational level

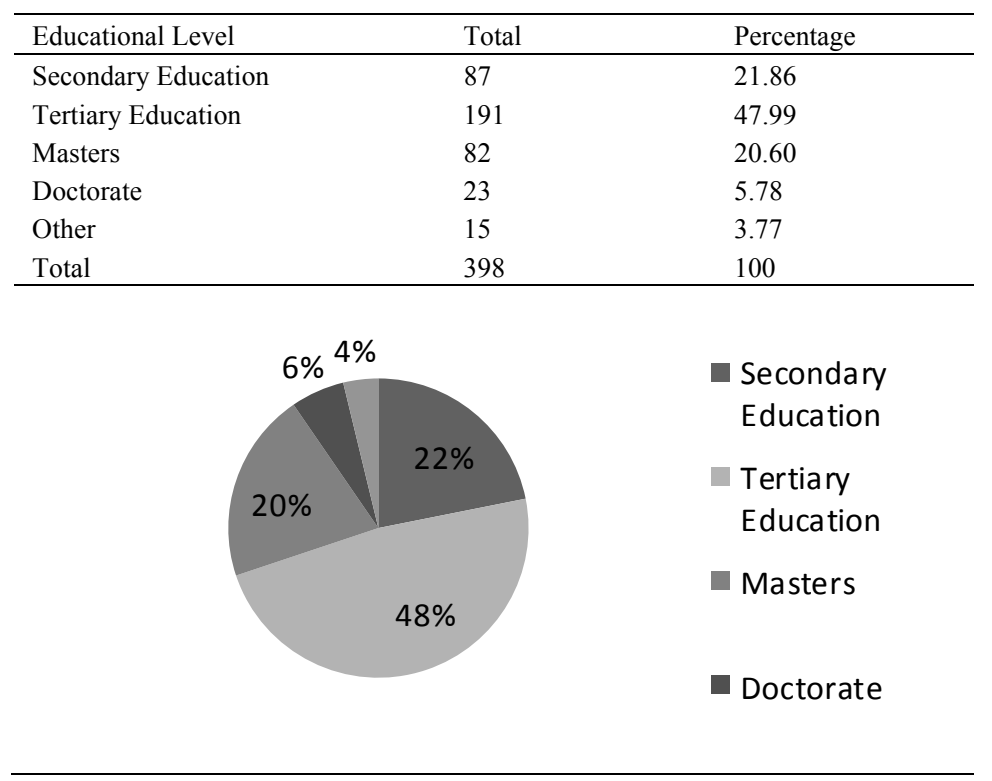

According to Table 5, $48 \%$ of the respondents had completed tertiary education, $22 \%$ had completed secondary education, $21 \%$ had a Master's degree and $6 \%$ a doctorate.

\subsection{Fast Food Consumption Patterns}

The second part of the questionnaire included five questions about fast food consumption, consumption frequency per type of fast food, opinions whether fast food is healthy or not, consumption criteria and factors that affect consumption, as well as four more general questions regarding fast food and globalization, Mediterranean diet, advertising and children targeting. The replies are presented below.

\subsubsection{Fast Food Consumption}

Question 2.1 of the questionnaire was a direct question whether the respondents consume fast food. The replies are presented below.

Table 6. Fast food consumption

\begin{tabular}{|c|c|c|}
\hline Answers & Total & Percentage \\
\hline Yes & 367 & 92.21 \\
\hline No & 31 & 7.79 \\
\hline Total & 398 & 100 \\
\hline
\end{tabular}


This question was replied from almost all the participants and an impressive $92 \%$ of them replied that they consume fast food.

\subsubsection{Consumption Frequency per Type of Fast Food}

The second question aimed at investigating the most popular fast food types for Greek consumers and the frequency of consumption. The options given as fast food types were burgers, sandwiches, hot-dogs, vegetarian sandwiches, gyros and souvlaki, crepes and pizzas.

Table 7. Consumption frequency per type of fast food

\begin{tabular}{lllllll}
\hline Type of Fast Food & Never & $\begin{array}{l}1-5 \text { times per } \\
\text { month }\end{array}$ & $\begin{array}{l}6-10 \text { times per } \\
\text { month }\end{array}$ & $\begin{array}{l}10-15 \text { times per } \\
\text { month }\end{array}$ & $\begin{array}{l}15+\text { times per } \\
\text { month }\end{array}$ & Total \\
\hline Burgers & 113 & 216 & 25 & 5 & 5 & 364 \\
Sandwiches and tosts & 72 & 235 & 44 & 26 & 21 & 398 \\
Hot dogs & 250 & 94 & 12 & 6 & 3 & 365 \\
Veg. sandwiches & 240 & 80 & 22 & 6 & 5 & 353 \\
Gyros and souvlaki & 39 & 217 & 54 & 25 & 7 & 354 \\
Crepes & 125 & 178 & 25 & 12 & 9 & 347 \\
Pizza & 28 & 233 & 47 & & & 332 \\
\hline
\end{tabular}

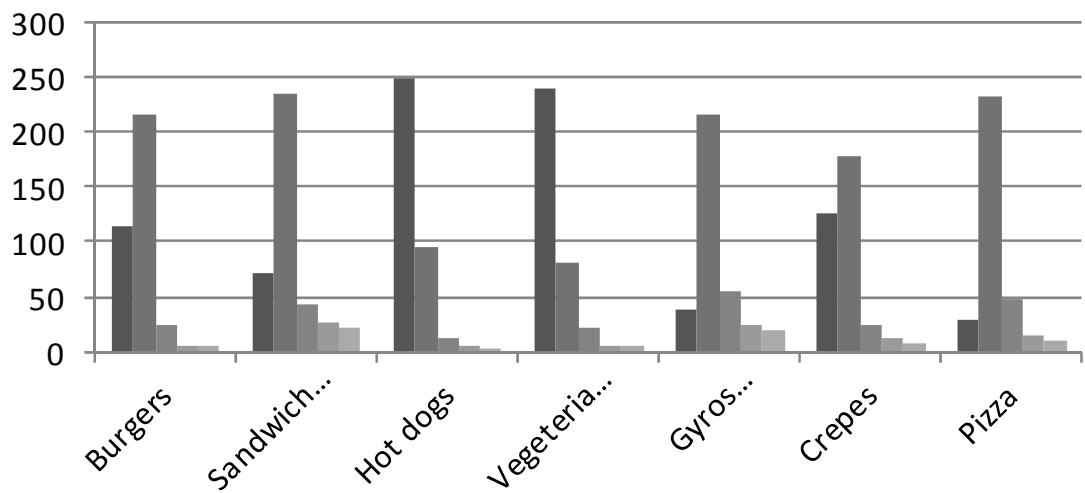

Never

1-5 times per month

6-10 times per month

10-15 times per month

15+times per month

From Table 7 it can be observed that the most popular fast food categories among Greek consumers were sandwiches and tosts, gyros and souvlaki, pizzas, and finally burgers. Less popular fast food-types were vegetarian sandwiches and hot-dogs. Most consumers consume fast food 1 to 5 times per month, however some of them answered that they consume sandwiches (21) and gyros (19) more than 15 times per month.

\subsubsection{Fast Food as a Healthy Eating Choice}

Question 4.2.3 was asking consumers whether they see fast food as a healthy eating choice. The available replies were Yes, No and Other, in case they didn't want to reply.

Table 8. Fast food as a healthy eating choice

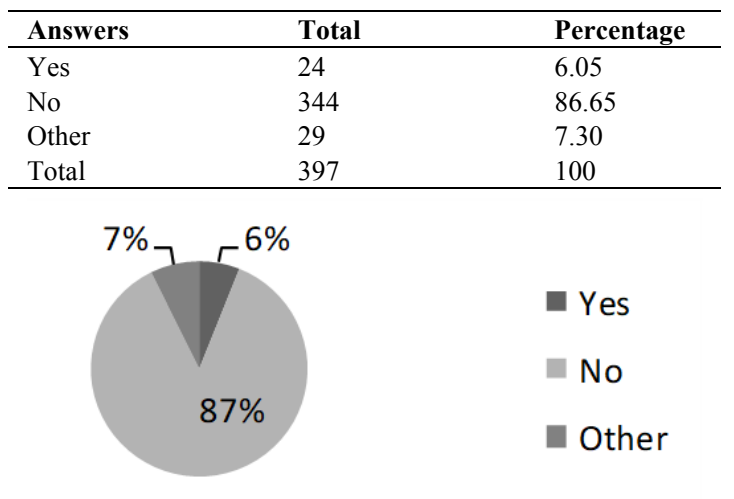


Surprisingly, almost $87 \%$ of the participants replied that they don't consider fast food as a healthy choice, while around $6 \%$ of them replied that fast food is healthy. Only $7 \%$ chose the Other option.

\subsubsection{Criteria for Choosing Fast Food}

The 4th question aimed at recording the criteria with which the Greek consumers choose fast food. The options given were taste, price, health and safety, convenience and proximity and finally quantity.

Table 9. Criteria for choosing fast-food

\begin{tabular}{lllllll}
\hline Factors & $\begin{array}{l}\text { Extremely } \\
\text { important }\end{array}$ & Very important & $\begin{array}{l}\text { Moderately } \\
\text { important }\end{array}$ & Slightly important & Not important & Total \\
\hline Taste & 224 & 114 & 17 & 5 & 4 & 364 \\
Price & 83 & 152 & 89 & 22 & 16 & 362 \\
Health \& Safety & 156 & 104 & 73 & 20 & 13 & 364 \\
Convenience \& Proximity & 115 & 139 & 80 & 25 & 7 & 361 \\
Quantity & 89 & 137 & 109 & & 7 & 367 \\
\hline
\end{tabular}

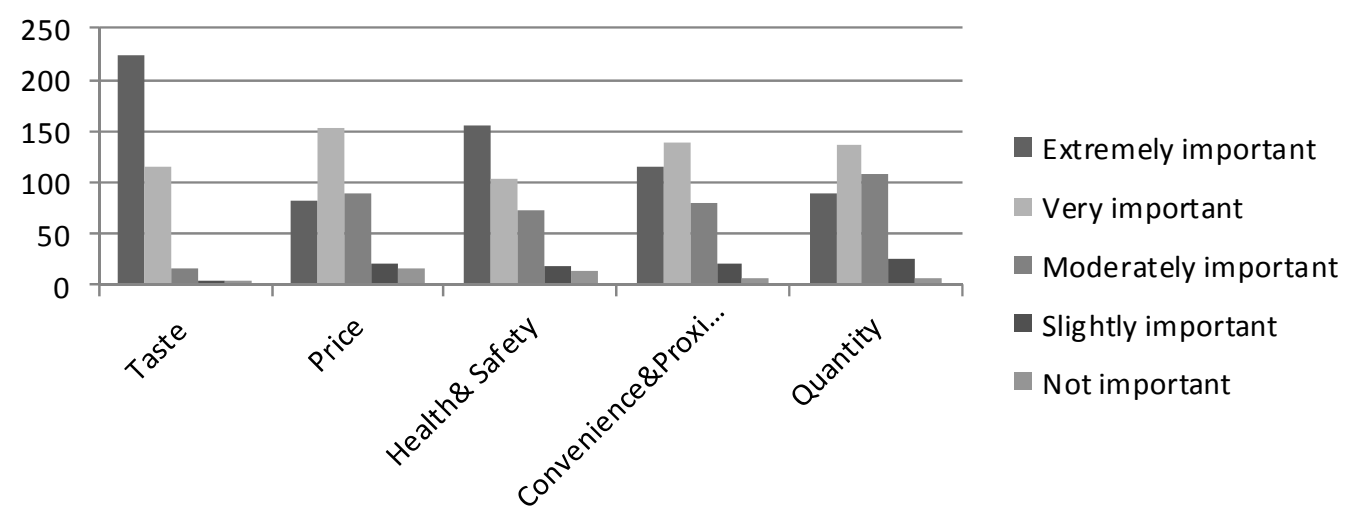

According to Table 9, the most important factor that Greek consumers take under consideration when selecting fast food is taste, followed by health and safety and third is convenience and proximity. It is surprising that price is not considered an extremely important criterion, as well as quantity.

\subsubsection{Factors Affecting Fast Food Consumption}

The 5th question was asking participants to rate the importance for them of a series of factors that may affect their buying behaviour in relation to fast food. These factors were mood, economic factors, family habits, brand awareness, ethics and finally socialising. The replies are presented in Table 10. 
Table 10. Factors affecting fast food consumption

\begin{tabular}{llllll}
\hline Factors & $\begin{array}{l}\text { Extremely } \\
\text { important }\end{array}$ & Very important & $\begin{array}{l}\text { Moderately } \\
\text { important }\end{array}$ & Slightly important & Not important \\
\hline Mood & 123 & 124 & 69 & 30 & 17 \\
Economic Factors & 83 & 129 & 54 & 34 & 23 \\
Family Habits & 56 & 93 & 107 & 46 & 47 \\
Brand Awareness & 29 & 90 & 110 & 65 & 65 \\
Ethics & 42 & 82 & 103 & 57 & 83 \\
Socializing & 37 & 82 & & 65 & 359 \\
\hline
\end{tabular}

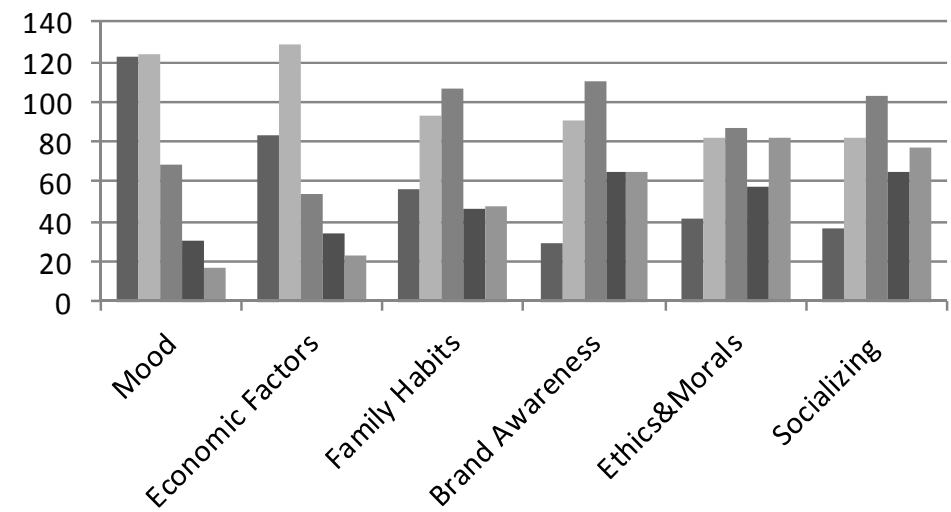

Extremely important

- Very important

Moderately important

- Slightly important

Not important

According to Table 10, the most important factor that affects Greek consumers buying behaviour is mood, followed by economic factors. Family habits are also an important factor for a large part of the sample. Brand awareness, ethics and socialising and do not seem to be among the important factors that affect the consumption of fast food for the largest share of participants.

\subsubsection{Fast Food Consumption and Globalization}

Question 6 of the second part of the questionnaire was asking the opinion of the respondents relatively to the role of globalization on food consumption. The exact question was "Do you think globalization is changing the food industry and the food buying behaviors?" The replies are presented in Table 11.

Table 11. Fast food consumption and globalization

\begin{tabular}{|c|c|c|}
\hline Answers & Total & Percentage \\
\hline Yes & 368 & 92.46 \\
\hline No & 27 & 6.78 \\
\hline Other & 3 & 0.75 \\
\hline Total & 398 & 100 \\
\hline
\end{tabular}

This question was replied from all the participants and $92 \%$ of them believed that the food industry is changing because of globalization.

4.2.7 Fast Food Consumption and Mediterranean Diet

Another important topic that affects food preferences and food consumption in Greece is Mediterranean diet, as 
pointed out in the literature review. Question 7 was asking the participants whether they think that the Mediterranean diet is being replaced by a more westernised diet. The replies are presented in Table 12.

Table 12. Fast food consumption and mediterranean diet

\begin{tabular}{lll}
\hline Answers & Total & Percentage \\
\hline Yes & 245 & 61.56 \\
No & 127 & 31.91 \\
Other & 26 & 6.53 \\
Total & 398 & 100 \\
\hline
\end{tabular}

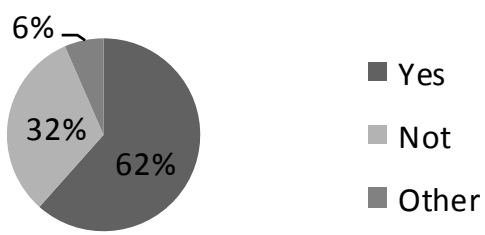

This was a question that was answered by almost all of the participants, out of which almost $62 \%$ replied positively, $32 \%$ replied negatively and $6 \%$ chose the Other option.

\subsubsection{Intense Marketing \& Advertising}

Question 8 was asking the participants whether they believed that intense marketing and advertising was influencing their fast food purchasing behaviours. Answers are presented in Table 13.

Table 13. Fast food consumption and intense marketing and advertising

\begin{tabular}{lll}
\hline Answers & Total & Percentage \\
\hline Yes & 263 & 65.33 \\
No & 128 & 32.16 \\
Other & 10 & 2.51 \\
Total & 398 & 100 \\
\hline
\end{tabular}

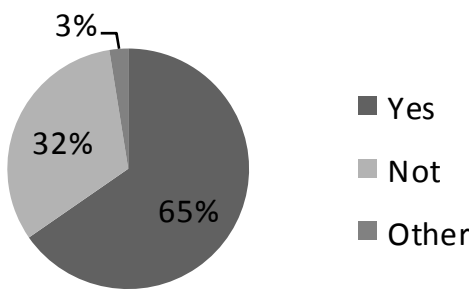

In this question $65 \%$ of the respondents replied Yes, meaning that they believed that their buying behaviours is affected by marketing, while $32 \%$ chose No, considering themselves unaffected by it.

\subsubsection{Fast Food Industry and Child Targeting}

The last question was asking participants whether the found the fast food industry unethical for targeting children. The goal of this question was to investigate their beliefs on this topic. 
Table 14. Fast food industry and child targeting

\begin{tabular}{lll}
\hline Answers & Total & Percentage \\
Yes & 289 & 72.61 \\
No & 88 & 22.11 \\
Other & 21 & 5.28 \\
Total & 398 & 100 \\
\hline
\end{tabular}

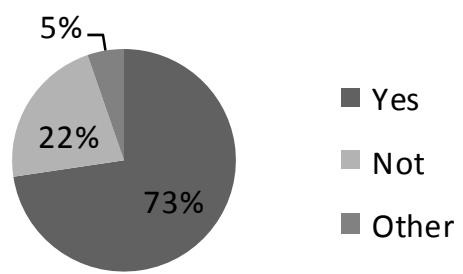

In this controversial subject $73 \%$ of the respondents have answered 'yes', whereas $22 \%$ disagreed, and about $5 \%$ of the respondents chose the Other opinion.

\subsection{Characteristics and Patterns of Customer Segments with Hishest Consumption Rates}

Apart from the presentation of the total results of the research, it would be useful to explore the characteristics and shopping criteria of the customer segment that had the highest consumption rate. This segment has been defined as those respondents that consume the two most popular types of fast-food (1. sandwiches and tosts, and 2. gyros and souvlaki) more frequently, with high frequency being defined as the combined consumption of both types of fast foods for more than 10 times per month. The main characteristics of this customer segment are the following:

- $\quad 60 \%$ are between $21-30$ and $18 \%$ between $31-40$

- $\quad 45 \%$ are male and $55 \%$ female

- $\quad 57 \%$ have an income below $10.000 €$ and $21 \%$ have and income between $10.000-14.000 €$

- $\quad 66 \%$ are not married

- $\quad 60 \%$ have finished higher education and $12 \%$ have a Masters

Regarding the factors that affect the shopping behaviour of this customer segment, the following observations have been recorded from the data analysis:

- Most of them also frequently consume crepes and pizzas

- $\quad 85 \%$ do not consider fast food healthy

- $\quad 63 \%$ consider the taste of fast food as extremely important

- $\quad 18 \%$ consider the price of fast food as extremely important

- $\quad 36 \%$ consider health and safety of fast food as extremely important

- $\quad 45 \%$ consider convenience of fast food as extremely important

- $\quad 3 \%$ consider the quantity of fast food as extremely important

- $\quad 24 \%$ are extremely affected by their mood

- $\quad 15 \%$ are extremely affected by economic factors

- $\quad 9 \%$ are extremely affected by family eating habits

- $\quad 3 \%$ are extremely affected by brand recognition

- $\quad 3 \%$ are extremely affected by ethics

- $\quad 0 \%$ are extremely affected by socialising

\subsection{Open-Ended Question}

The third and final section of the questionnaire included one open-ended question relating to fast food and some open space for general comments. The question was: "What is the first thing that comes to your mind when you 
hear the phrase fast food?" The aim of this question was to capture the spontaneous thoughts of the participants in relation to fast food. This question was answered by $95 \%$ of the participants. The vast majority (46\%) answered a kind of fast food, with most popular answers being "Gyros", "Souvlaki", "Burger", "Pizza" and "Sandwich". Fewer answered by naming fast food chains, such as "Goody's" and "MacDonald's". It is noteworthy that the next word that appeared in the majority of answers is "unhealthy" with $9 \%$. The next answer was the word "delicious" or "tasty" (6\%), while $4.75 \%$ answered that fast food means "convenience" and "no cooking". Almost the same percentage (4.5\%) answered words related to fattening, such as "fat", "calories", "obesity". The next answer, which accounted for $4 \%$, was "time saving", while 3\% replied that fast food is "non-quality food", $2 \%$ responded using the word "dirty" and $1 \%$ "junk, sloppy". Adding these last three answers, we conclude that $6 \%$ associates fast food with low quality food that has no nutrients or is "plastic", "toxic" or "dirty" to quote some of the answers given. It is worth mentioning that $2 \%$ responded with the words "cheap, low cost". Finally, 14\% gave other answers.

The last part of the questionnaire provided the option for general comments. Many of the respondents chose to congratulate the researchers. Other comments expressed the opinion that homemade food is much healthier, that fast food is consumed because of shortage of time, that fast food is unhealthy and that in small cities local fast foods are supplied by local producers, making the fast food ingredients healthier. Other respondents also mentioned the need for strict control of fast food businesses and their suppliers by public authorities.

\section{Discussion}

The results of the research can provide a relatively good picture of Greek consumers' fast food consumption patterns and preferences. Fast food is very popular among Greeks, as $92 \%$ of the respondents answered that they consume fast food. Most respondents consume fast food 1-5 times per month, and usually they consume sandwiches and tosts, gyros and souvlaki as well as pizza. It is striking that $86 \%$ of the respondents consider fast food unhealthy, but they still consume it. The most important factor they take under consideration when selecting fast food is taste, followed by health and safety and third is convenience and proximity. It is surprising that price is not considered an extremely important criterion, as well as quantity. Regarding the factors that affect Greek consumers' buying behaviour, the most important one was mood, followed by economic factors. Family habits were also an important factor for a large part of the sample. From the more general questions, it was recorded that $92 \%$ of them believed that the food industry is changing because of globalization, $62 \%$ believed that the Mediterranean diet is being replaced by western-type foods, and $65 \%$ of the respondents believed that their buying behaviours are affected by companies' marketing strategies. In the controversial topic of children targeting $73 \%$ of the respondents considered that it is unethical to target children.

\section{Conclusions}

In most countries of the world people frequently satisfy their nutritional needs by selecting to consume "inexpensive foods served in restaurant chains, where orders are served promptly at a counter" (Smith, 2012, p. 316) or shortly fast foods. The explosion of fast food consumption during the last 50 years was due to a number of factors, including low cost, speed and convenience. However, despite its practicality, fast food is typically characterized as low-quality food and has been related with various health problems like obesity.

The goal of this particular research was to investigate the eating habits and preferences of Greeks in regard to fast food. Particularly, the research aimed to investigate whether people in Greece consume fast food and how frequently, the types of fast food they prefer, the criteria for choosing fast food and the factors that affect their consumption patterns. From the analysis of the results it was shown that fast food is very popular among Greeks, as $92 \%$ of the respondents answered that they consume fast food, and most people consume fast food 1-5 times per month. Usually they consume sandwiches and tosts, gyros and souvlaki as well as pizza. The most important criterion for selecting fast food is taste, followed by health and safety and third is convenience and proximity. Regarding the factors that affect Greek consumers' buying behaviour, the respondent' replied pointed out mood, followed by economic factors and family habits. Also, most of the Greeks consider fast food unhealthy, but they still consume it.

From the results of the research and their analysis certain conclusions can be drawn. Greek customers consume fast food and it is most likely that they will continue to consume it. However, most of the people consider it unhealthy. This observation in conjunction with the observation that the most important factor when selecting fast food is taste and safety and not price, means that there is a clear need for healthy, tasty, easily accessible and not necessarily low-cost fast food. Keeping in mind the fact that mood was also a factor that affects consumption, fast food businesses will require well designed outlets that will relax and inspire the apetite of customers. 


\section{References}

Adams, R. (2005). Fast Food, Obesity, and Tort Reform: An Examination of Industry Responsibility for Public Health. Business \& Society Review, 110(3), 297-320. https://doi.org/10.1111/j.0045-3609.2005.00017.x

Allahar, H. (2015). Consumer Behavior and the Growth of the Fast Food Industry in a Small Emerging Country. International Journal of Advances in Management and Economics, 4(3), 180-189.

Buttriss, J., Deakin, K., \& Smith, E. (2003). Promotion of foods to children-to ban or not to ban? Nutrition Bulletin, 28(1), 43-46. https://doi.org/10.1046/j.1467-3010.2003.00293.x

Byrne, P., Capps, Jr., O., \& Saha, A. (1996). Analysis of Food Away from Home Expenditure Patterns for U.S. Households. American Journal of Agricultural Economics, 78(3), 614-627. https://doi.org/10.2307/1243279

Davis, B., \& Carpenter, C. (2009). Proximity of fast food restaurants to schools and adolescent obesity. American Journal of Public Health, 99(3), 505-515. https://doi.org/10.2105/AJPH.2008.137638

Dentoni, D., Tonsor, G., Calantone, R., \& Peterson, H. C. (2011). 'Animal Welfare' Practices along the Food Chain: How Does Negative and Positive Information Affect Consumers? Journal of Food Products Marketing, 17(2/3), 279-302. https://doi.org/10.1080/10454446.2011.548720

Egan, J. (2007). Marketing Communications. London: Jennifer Pegg.

Euromonitor International. (2018). Fast Food in Greece. Retrieved March 6, 2018, from https://www.euromonitor.com/fast food-in-greece/report

Fullerton, R. (2011). The Birth of Consumer Behavior: Motivation Research in the 1950s. Journal of Historical Research in Marketing, 5(2), 212-222. https://doi.org/10.1108/17557501311316833

Gardner, B. B. (1959). The ABC of Motivation Research. Business Topics, 7, 35-41.

Giannatou, L. (2013). Greeks turning away from fast food chains in favor of traditional snacks. Kathimerini. Retrieved May 20, 2018, from http://www.ekathimerini.com

Gregory, S., McTyre, C., \& DiPietro, R. (2006). Fast Food to Healthy Food: A Paradigm Shift. International. Journal of Hospitality \& Tourism Administration, 7(4), 43-64. https://doi.org/10.1300/J149v07n04_03

Grunert, K. G. (2005) Food quality and safety: consumer perception and demand. European Review of Agricultural Economics, 32(3), 369-391. https://doi.org/10.1093/eurrag/jbi011

Hellenic Statistical Authority. (2018). Greece in Figures. ELSTAT.

Hu, F. (2003). The Mediterranean Diet and Mortality-Olive Oil and Beyond. The New England Journal of Medicine, 348(26), 2595-2596. https://doi.org/10.1056/NEJMp030069

Jekanowski, M., Binkley, J., \& Eales, J. (2001). Convenience, Accessibility, and the Demand for Fast Food. Journal of Agricultural and Resource Economics, 26(1), 58-74.

Keys, A. B., \& Keys, M. (1975). How to eat well and stay well the Mediterranean way. New York, USA: Doubleday Publishing.

Khan, M. (2008). Consumer Behaviour. New Age International Publishers.

Kinsey, J. (1983). Working Wives and the Marginal Propensity to Consume Food Away from Home. American Journal of Agricultural Economics, 65(1), 10-19. https://doi.org/10.2307/1240332

Kromhout, D., Menotti, A., \& Blackburn, H. (1994). The Seven Countries Study: A scientific adventure in cardiovascular disease epidemiology. Brouwer.

Lacirignola, C., \& Capone, R. (2015). Mediterranean food consumption patterns: Diet, environment, society, economy and health. FAO, Rome.

Marlow, M., \& Shiers, A. (2012). The relationship between fast food and obesity. Applied Economics Letters, 19(16), 1-5. https://doi.org/10.1080/13504851.2011.648316

Martineau, P. (1957). Motivation in Advertising. McGraw Hill.

Moss, M. (2013). Salt, Sugar, Fat: How the Food Giants Hooked Us. New York: Random House.

Noel, H. (2009). Basics Marketing 01: Consumer Behaviour. Lausanne: AVA Publishing SA. https://doi.org/10.5040/9781350088825

Poti, J., Duffey, K., \& Popkin, B. (2014). The association of fast food consumption with poor dietary outcomes 
and obesity among children: is it the fast food or the remainder of the diet? The American Journal of Clinical Nutrition, 99, 162-171. https://doi.org/10.3945/ajen.113.071928

Schiffman, L., O’Cass, A., Paladino, A., \& Carlson, J. (2014). Consumer Behaviour (6th ed.). Pearson.

Schlosser, E. (2012). Fast Food Nation: The Dark Side of the All-American Meal. Houghton Mifflin.

Sexauer, B. (1979). The Effects of Demographic Shifts and Changes in the Income Distribution of Food-Away from-Home Expenditure. American Journal of Agricultural Economics, 61(3), 1046-1057. https://doi.org/10.2307/3180373

Smith, A. (2012). Fast Food and Junk Food - An Encyclopedia of What We Love to Eat. Greenwood.

Solomon, M., Bennett, R., \& Previte, J. (2013). Consumer behaviour: buying, having, being (3rd ed.). Pearson Australia.

Trichopoulou, A., Martínez-González, M., Tong, T., Forouhi, N., Khandelwal, S., Prabhakaran, D., Mozaffarian, D., \& Michel, d. L. (2014). Definitions and potential health benefits of the Mediterranean diet: views from experts around the world. BMC Medicine, 12, 112. https://doi.org/10.1186/1741-7015-12-112

Vernele, L., Bach-Faig, A., Buckland, G., \& Serra-Majem, L. (2010). Association between the Mediterranean diet and cancer risk: a review of observational studies. Nutrition and Cancer, 62(7), 860-870. https://doi.org/10.1080/01635581.2010.509834

Wansink, B. (2004). Environmental factors that increase the food intake and consumption volume of unknowing consumers. Annual Review of Nutrition, 24, 455-479. https://doi.org/10.1146/annurev.nutr.24.012003.132140

\section{Copyrights}

Copyright for this article is retained by the author, with first publication rights granted to the journal.

This is an open-access article distributed under the terms and conditions of the Creative Commons Attribution license (http://creativecommons.org/licenses/by/4.0/). 